\title{
Refrigeration capacity of silver nanofluids under electrohydrodynamic effect oriented to heat removal in machining process ${ }^{\text {ht }}$
}

\author{
Renan Luis Fragelli*, Luiz Eduardo de Angelo Sanchez, Rubens Roberto Ingraci Neto, \\ Vicente Luiz Scalon \\ Sao Paulo State University - UNESP, Department of Mechanical Engineering, Luiz Edmundo Carrijo Coube Avenue 14-01, Bauru, Sao Paulo 17033-360, Brazil
}

\section{A R T I C L E I N F O}

\section{Keywords:}

Nanofluids

Heat transfer

Electrohydrodynamic effect

Silver nanoparticles

Surface deposition

\begin{abstract}
A B S T R A C T
Nanofluids have been the focus of many laboratories and research centres which seek practical applications for them. Considering the challenges in machining process related with the high temperature in the cutting zone and its influence on the tool life, in this study the nanofluids are employed in a system analogous to the an internally cooled toolholder which can eliminate the use of cutting fluids. In this way, the purpose of this work consists in evaluate the influence of addition of silver nanoparticles in different concentrations in a solution of ethylene glycol/DI-water on the heat transfer coefficient. Moreover, inside the system, the nanofluids were subjected to an electric field in the heat transfer region in order to analyse the influence of the electrohydrodynamic effect. The tests showed that the nanoparticles influenced the fluid viscosity increasing its value up to $20.3 \%$ in higher concentrations and also influenced the convective heat transfer coefficient $(h)$. Furthermore, it was presented a positive influence of the electric field enhancing the value of the convective heat transfer coefficient $(h)$ up to $11 \%$ when the concentration was 0.039 vol\%. On the other hand, the nanoparticle deposition on the heated surface resulted in reduction of the heat transfer coefficient.
\end{abstract}

\section{Introduction}

Advances in nanotechnology have allowed the emergence of a new generation of refrigerants known as nanofluids. They are, basically, colloidal suspensions composed of solid nanoparticles with a maximum size of $100 \mathrm{~nm}$ immersed in a base fluid [1]. Water, organic liquids (ethylene glycol, ethylene, refrigerants, etc.), oils and lubricants, biofluids and polymer solutions are some of the base fluids that can be used. Nanoparticles can consist of a wide range of materials, such as: chemically stable metals (gold, copper), oxides in general (alumina, silica, zirconium, titanium, copper), metal carbides ( $\mathrm{SiC})$, carbon in various forms (graphite, graphene, carbon nanotubes, fullerene) and functionalized nanoparticles [2].

Improvement of the heat transfer capacity of a fluid can increase the amount of thermal energy transferred in the same surface area or reduce the size of any given equipment by maintaining the heat transfer rate. According to Laohalertdecha et al. [3], there are two techniques that are used to optimize the thermal transfer: passive and active. The passive technique deals with addition of elements in a fluid or the use of special surfaces (rough, extended, etc.). In turn, the active one is about the application of external forces, such as vibration (surface or acoustic) or electric field.

According to several authors [1,4-8], the thermal conductivity of nanofluids is influenced by some factors such as: temperature, concentration, composition, shape and size of nanoparticles. An increase in temperature and concentration has the effect of raising the nanofluid's thermal conductivity. Also, the more elongated the nanoparticle is, the greater is the increase in the thermal conductivity. In addition, surfactants ensure greater stability to the nanofluid by avoiding the deposition and cluster formation of nanoparticles. This deposition can influence positively or negatively the heat transfer coefficient.

Another factor that affects a thermal conductivity of nanofluids is the presence of a nanolayer. Yu and Choi [9] developed a new model to predict the thermal conductivity considering the presence of solid-like nanolayer. The layer acts as a thermal bridge between liquid bulk and nanoparticle and results in a thermal conductivity enhancement. According to $\mathrm{Yu}$ et al. [10], the thermal conductivity of the nanolayer on the surface of the nanoparticle is not known. However, since the layered molecules are in an intermediate physical state between a bulk liquid and a solid, the solid-like nanolayer of liquid molecules would be

\footnotetext{
This research did not receive any specific grant from funding agencies in the public, commercial, or not-for-profit sectors.

* Corresponding author.

E-mail addresses: renan.fragelli@gmail.com, renan.fragelli@unesp.br (R.L. Fragelli), sanchez@feb.unesp.br (L.E.d.A. Sanchez), rubens.ingraci@yahoo.com.br, rubens.ingraci@unesp.br (R.R. Ingraci Neto), scalon@feb.unesp.br (V.L. Scalon).
} 


$\begin{array}{ll}\text { Nomenclature } \\ h & \text { convective heat transfer coefficient }\left(\mathrm{W} / \mathrm{m}^{2} \cdot \mathrm{K}\right) \\ \theta_{(x)} & \text { excess of temperature in a specific point of the fin }\left({ }^{\circ} \mathrm{C}\right) \\ \theta_{b} & \text { excess of temperature at the base of the fin }\left({ }^{\circ} \mathrm{C}\right) \\ m & \text { fin parameter }\left(\mathrm{m}^{-1}\right) \\ L & \text { fin length }(\mathrm{m}) \\ x & \text { distance from fin base }(\mathrm{m}) \\ T_{\infty} & \text { mean temperature at the fluid }\left({ }^{\circ} \mathrm{C}\right) \\ T_{b} & \text { temperature in the fin base }\left({ }^{\circ} \mathrm{C}\right) \\ T_{i n} & \text { inlet temperature }\left({ }^{\circ} \mathrm{C}\right) \\ T_{\text {out }} & \text { outlet temperature }\left({ }^{\circ} \mathrm{C}\right) \\ T_{\text {exp }} & \text { experimental temperatures }\left({ }^{\circ} \mathrm{C}\right) \\ P & \text { perimeter (m) } \\ k & \text { thermal conductivity }(\mathrm{W} / \mathrm{m} \cdot \mathrm{k}) \\ \text { Atr } & \text { cross-section area }\left(\mathrm{m}^{2}\right) \\ \mu & \text { viscosity (mPas }) \\ \mu_{n f} & \text { viscosity of nanofluid }(\mathrm{mPa} \cdot \mathrm{s}) \\ \mu_{f} & \text { viscosity of base fluid }(\mathrm{mPa} \cdot \mathrm{s}) \\ c_{p} & \text { specific heat capacity }(\mathrm{J} / \mathrm{kg} \cdot \mathrm{K})\end{array}$

expected to lead to a higher thermal conductivity than that of the bulk liquid.

In order to understand the mechanisms involved in the increase of thermal transfer under convection conditions, Buongiorno [11], states that one of these reasons is the Brownian motion. It is the movement of nanoparticles within the base fluid in consequence of continuous collisions between the nanoparticles and the molecules of the base fluid. The nanoparticles themselves can be viewed effectively as large molecules, with an average kinetic energy equal to that of the fluid molecules and thus with a considerable lower velocity. In this way, heat transfer occurs more intensively because of these collisions.

The thermal conductivity of nanofluids containing $\mathrm{Al}_{2} \mathrm{O}_{3}, \mathrm{CuO}$ and $\mathrm{Cu}$ in two different base fluids (water and HE-200 oil) was measured by Eastman et al. [7]. Under a volumetric concentration of $5 \%$ it was possible to achieve an increase of $60 \%$ in thermal conductivity compared to the base fluid.

The effects of temperature and concentration were experimentally studied by Harandi et al. [12] for nanofluids produced by the two step method with functionalized multi-walled carbon nanotubes (fMWCNTs) and $\mathrm{Fe}_{3} \mathrm{O}_{4}$ nanoparticles dispersed in ethylene glycol (EG). The volumetric concentration varied from $1 \%, 0.25 \%, 0.45 \%, 0.8 \%$, $1.25 \%, 1.8 \%$ and $2.3 \%$ and the temperature from $25^{\circ} \mathrm{C}$ to $50{ }^{\circ} \mathrm{C}$. An enhancement in the thermal conductivity with increasing the temperature and volumetric concentration was achieved and, in lower temperatures, the variation of thermal conductivity ratio with solid volume fraction was less than that at higher temperatures. With $2.3 \mathrm{vol}$ $\%$ and temperature of $50{ }^{\circ} \mathrm{C}$, a maximum thermal conductivity of $30 \%$ was achieved.

Lee et al. [4] dispersed $\mathrm{CuO}$ and $\mathrm{Al}_{2} \mathrm{O}_{3}$ nanoparticles in water and ethylene glycol (EG) resulting in 4 different nanofluids: $\mathrm{CuO} / \mathrm{EG}, \mathrm{CuO} /$ water, $\mathrm{Al}_{2} \mathrm{O}_{3} / \mathrm{EG}$ and $\mathrm{Al}_{2} \mathrm{O}_{3}$ /water. Among these four nanofluids, the $\mathrm{CuO} / \mathrm{EG}$ containing $4 \mathrm{vol} \%$ showed the best performance resulting in an increase of $20 \%$ in the thermal conductivity.

In a study using deionized water and EG as base fluids, nano and microparticles of silicon carbide (SiC) with mean diameter of $26 \mathrm{~nm}$ and $0.6 \mu \mathrm{m}$, respectively, Xie et al. [13,14] compared the thermal conductivity of both types of fluids by the transient hot-wire method. The authors found that the same type of element, although of different sizes and base fluids, produced the same increase in thermal conductivity. Moreover, the results showed that the mathematical model of Hamilton and Crosser (1962) is able to predict the thermal conductivity for particles $(\mathrm{SiC})$ with $0.6 \mu \mathrm{m}$ in diameter, whereas this was not possible for particles in nanoscale. arithmetic average roughness $(\mu \mathrm{m})$

Reynolds number

Nusselt number

volumetric concentration (\%)

fluid speed $(\mathrm{m} / \mathrm{s})$

diameter of fin (m)

fluid flow (L/min)

specific mass $\left(\mathrm{kg} / \mathrm{m}^{3}\right)$

Subscripts

EG ethylene glycol

DI-water deionized water

CNT carbon nanotubes

$E H D \quad$ electrohydrodynamic effect

$P U$ polyurethane

SEM scanning electronic microscopy

EDS energy dispersive X-ray spectroscopy
Using the same type of nanoparticle, Lee et al. [15] analyzed the dispersion behavior for $\mathrm{SiC} / \mathrm{DI}$-water nanofluids in different $\mathrm{pH}$ values. Then, because of the different volume fraction of nanoparticles, the viscosity and thermal conductivity were investigated to evaluate the potential of the nanofluids to work in heat transfer applications. Five $\mathrm{SiC} / \mathrm{DI}$-water nanofluids with different volumetric concentration $(0.001 \%, 0.1 \%, 1 \%, 2 \%$ and $3 \%)$ were prepared. The authors found out that the viscosity of SiC/DI-water nanofluids increases with an increase of particle volume fraction and they alert that a large increase of viscosity may result in a decrease of the potential benefits of nanofluids.

Considering the effect of concentration and temperature on the dynamic viscosity, Baratpour et al. [16] utilized SWCNT/EG and found out that the viscosity achieved an increase of 3.18 times in a temperature of $30^{\circ} \mathrm{C}$ and $0.1 \mathrm{vol} \%$, when compared with the base fluid. Moreover, the authors took the experimental data to develop a new correlation with acceptable accuracy.

Aghabozorg et al. [5] studied the effect of different concentrations of carbon nanotubes (CNT) and magnetite $\left(\mathrm{Fe}_{3} \mathrm{O}_{4}\right)$ on water (Fe-CNT/ $\mathrm{H}_{2} \mathrm{O}$ ) in the convective heat transfer coefficient. Mass fractions of $0.1 \%$ and $0.2 \%$ were used in laminar, transition and turbulent flow regimes. The results showed that the value of the heat transfer coefficient increased $13.54 \%$ and $27.69 \%$ for the lowest concentration and $34 \%$ and $37.5 \%$ for the highest concentration in laminar and turbulent regimes, respectively.

The effect of temperature on the thermal conductivity of nanofluids containing $\mathrm{CuO}$ and $\mathrm{Al}_{2} \mathrm{O}_{3}$ was studied by Das et al. [8]. The authors found that it is possible to double or even quadruple the thermal conductivity when the temperature is increased from $21^{\circ} \mathrm{C}$ to $52^{\circ} \mathrm{C}$. Thus, this study suggests the application of nanofluids in equipment where the fluid will work at a temperature higher than the ambient and with high amount of energy to be dissipated.

Remarkable improvements in the efficiency of solar heating systems were observed by Gorji and Ranjbar [6] with the aid of nanofluids. The authors carried out a numerical and experimental study with three types of nanoparticles dispersed in deionized water: graphite, magnetite and silver. The temperature distribution of the fluid within the solar collector was simulated using a computational model. Simultaneously, physical experiments were performed to validate the numerical model and investigate the effect of thermal flux intensity, nanoparticle concentration and nanofluids fluxes on the collector efficiency. According to the results, the nanofluids promoted an increase from $33 \%$ to $57 \%$ in energy absorption relative to the base fluid.

The lattice Bolzmann method (LBM) was used in many researches to 
study the heat transfer in different conditions as a copper-water nanofluid in a microchannel in slip flow regime; a numerically study of forced convection heat transfer of water-Ag, water-Cu and water- $\mathrm{Al}_{2} \mathrm{O}_{3}$ nanofluid in a microchannel; and the study of the laminar mixed convection of Cu-water nanofluid in an inclined shallow driven cavity which confirmed the appropriate ability of LBM to simulate the mixed convection of nanofluid in this condition [17-19].

Henderson et al. [20] analyzed the influence in the convective heat transfer coefficient $(h)$ of $\mathrm{SiO}_{2}$ nanoparticles in R134a refrigerant at concentrations of $0.05 \mathrm{vol} \%$ and $0.5 \mathrm{vol} \%$. A concentric counter flow heat exchanger made of cooper was adopted as test section. The refrigerant flowed through the inner tube, while hot water flowed in the outer tube. For both concentrations, the heat transfer coefficient value reduced in $43 \%$ and $55 \%$, respectively, compared to the base fluid. The authors credited the result to the formation of a layer of nanoparticles on the heated surface and to the low stability of the nanofluid that resulted in nanoparticles deposition.

In agreement with the results obtained by Henderson et al. [20], although under different conditions, Park et al. [21] analyzed four different concentrations of nanofluids with CNT dispersed in water. The volumetric concentrations used were $0.0001 \%, 0.001 \%, 0.01 \%$ and $0.05 \%$ and the convective heat transfer coefficient was reduced in $7.4 \%, 22.3 \%, 34 \%$ and $38.2 \%$, respectively, relative to its base fluid.

In a research which five different nanofluids were used, Moreira et al. [22] analyzed the influence of the nanoparticles on the heat transfer coefficient during flow boiling in a small diameter channel. Attention was given to analyze the effect of nanoparticles deposition on the heat transfer coefficient. The authors carried out texture characterization and surface roughness analyzes to compare the heated surface before and after the tests. Considering the results, the concentration and dimension of nanoparticles have influence in the heat transfer coefficient. For smaller nanoparticles the deposition had a different behavior (remarkable valleys and peaks) compared to bigger nanoparticles and this different behavior contributed to a reduction in the heat transfer coefficient due to the effect of the layer formed on the heated surface and its consequences on the density of active nucleation sites.

In order to optimize even more the thermal transfer of fluids, the application of the Electrohydrodynamic Effect (EHD) merged as an option. This effect is a consequence of the application of an electric field under a dielectric fluid in the region where the heat transfer takes place [3]. According to Allen and Karayiannis [23], there are three main forms of Electrohydrodynamic Effect (EHD) to act on a fluid toward increase of the convection heat transfer without phase change: corona effect, electrophoresis and dielectrophoresis.

When the electric field acts on the present ions an internal movement of the fluid known as the Corona effect starts. According to Robinson M. [24], the ions present in the fluid begin to move, influenced by the electric field. Thus, this movement will result in a large number of collisions between molecules that do not suffer the effect of the electric field and ions, resulting in a global fluid movement.

In cases where the EHD effect is induced by the electrophoresis, colloidal particles or polyelectrolytes immersed in a liquid start to move within the fluid due to the electric field influence. This movement seems to be the one which affects more the thermal transfer and its efficiency depends on the purity of these particles, type of fluid used and if it is polar or non-polar and whether some kind of charge is applied to the fluid [23].

In addition, the Electrohydrodynamic Effect can be caused by the dielectrophoresis where, due to a non-uniform electric field, the bulk liquid is polarized to move toward regions of high electric field strength [25].

Asadzadeh et al. [26] examined the changes in the thermal transfer by natural convection due to the application of an electric field near to a heated platinum wire immersed in a nanofluid. $\mathrm{Fe}_{3} \mathrm{O}_{4}$ nanoparticles in volumetric concentrations of $0.015 \%, 0.02 \%, 0.05 \%$ and $0.1 \%$ were dispersed in ethylene glycol. Nanoparticles collaborated positively up to $0.02 \mathrm{vol} \%$, which resulted in a higher convective heat transfer coefficient. However, for volumetric concentrations higher than $0.02 \%$, the heat transfer was reduced. The Electrohydrodynamic effect (EHD) contributed to an increase of the heat transfer and the greater the intensity of the electric field was, the greater was the increase of the thermal transfer coefficient. The highest value of the natural convection heat transfer coefficient was reached at a concentration of $0.02 \%$ with the application of the electric field.

Heris et al. [27] studied the effect of the electric field on the thermal efficiency of a thermosyphon with phase change. Two types of nanofluids produced by the ultrasonic vibration process were used: $\mathrm{Al}_{2} \mathrm{O}_{3}$ / water and $\mathrm{CuO} /$ water. Both nanofluids were free of dispersants in order to avoid changing their chemical properties. The results demonstrated that the performance of the thermosyphon increased with higher electric field intensity and nanoparticle concentration. It was also found that the action of nanoparticles on the performance of the thermosyphon was greater than the action of the electric field. The $\mathrm{Al}_{2} \mathrm{O}_{3}$ nanofluid had the best results and, according to the authors, this is due to the smaller size and great mobility of $\mathrm{Al}_{2} \mathrm{O}_{3}$ nanoparticles within the fluid, which directly influenced the breakage of the formed bubbles.

The use of cutting fluid is one of the biggest problems in machining processes, since it can represent up to $17 \%$ of the total costs involved in the production of a piece [28] and it is highly damaging to the environment and to the health of the workers [29]. For this reason, one of the main topics of study in machining is concentrated in the attempt to substitute the use of cutting fluids by methods of refrigeration that, at least, do not diminish the tool life. Among some methods, the indirect cooling, which is based on the internal cooling of the toolholder, has been highlighted. This can be verified by the increase in the number of researches and patents in this field [30-37]. However, no work employing internal cooling method provided sufficient performance for the complete elimination of the cutting fluid. A relevant attempt, not yet found in the literature, would be the increase of the internal cooling capacity of the toolholder by means of nanofluids.

The objective of this study is to evaluate the possibility of the utilization of nanofluids combined with the action of the electrohydrodynamic effect with the purpose of increasing the heat extraction capacity from the machining cutting zone with the use of the indirect cooling method in a toolholder. For this, a thermal transfer device with characteristics analogous to the region where the heat extraction of the cutting tool takes place in an internally cooled toolholder is proposed. The reason to setup the device out of tool machine, in laboratory, is due to the greater number of possibilities for testing, since each new modification of the tool holder would involve time and cost to its design and manufacture. Therefore, the device proposed is easier and simpler to operate than a real internally cooled toolholder, allowing the results obtained for different types of nanofluids, nanoparticle concentration and electric field intensity to be transferred to the machining process after the best solution have been found. More specifically, this device is analogous to the toolholder developed by Ingraci et al. [38], which presented the most promising results among the internally cooled toolholder found in the literature even considering that its performance is not yet sufficient to eliminate the cutting fluid in difficult-to-machining steels.

\section{Experimental apparatus and procedure}

\subsection{Heat chamber}

In order to evaluate the application of nanofluids and the Electrohydrodinamic Effect (EHD) in conditions of external forced convection, similar to the internally cooled toolholder condition, an experimental apparatus was developed. The illustration of the heating chamber, which is the main component of the system, is shown in Fig. 1. This chamber is composed of a copper $\operatorname{rod}(k=401 \mathrm{~W} / \mathrm{m} \cdot \mathrm{K})$ 


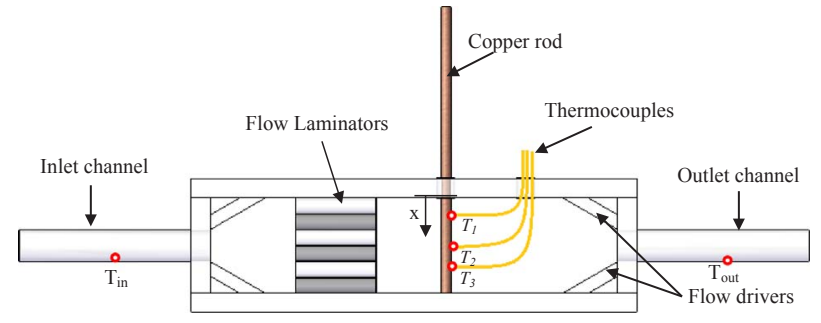

Fig. 1. Heat Chamber and its components.

which is heated in its outer part to the chamber. The inlet and outlet channels are made of polyurethane (PU) hose with $8 \mathrm{~mm}$ of internal diameter. The structure of the heating chamber is composed of transparent glass plates with thickness of $8 \mathrm{~mm}$. Flow drivers were used in order to guide the flow of nanofluid and to avoid regions of fluid stagnation. Finally, as can be verified, five k-type thermocouples were used to acquire the temperature at different points on the copper rod and the inlet and outlet temperatures of the fluid. The dimensions of the interior of the chamber were $140 \mathrm{~mm}$ length, $30 \mathrm{~mm}$ height and $10 \mathrm{~mm}$ width.

The information related to the geometry of the rod and the position of the thermocouples will be used in the mathematical development of the amount of heat dissipated by the copper rod, which will be considered a fin. The important information are the diameter of the rod $(5 \mathrm{~mm})$, length $(30 \mathrm{~mm})$ and the distances from the thermocouple position in relation to the base point $\left(T_{1}=8 \mathrm{~mm} ; T_{2}=17 \mathrm{~mm}\right.$; $T_{3}=25.5 \mathrm{~mm}$ ).

A heater that supplied the system with a constant power of $60 \mathrm{~W}$ was used to heat the rod and reach similar temperatures of the toolholder developed by Ingraci et al. [38]. In addition, the part of the rod outer, the heat chamber and the heater were thermally insulated by means of a ceramic fiber blanket to prevent the generated heat from being lost to the environment.

In order to test the nanofluid in the heating chamber, a circulation system was developed. In addition to the heating chamber and the heater, which have already been mentioned, the system was equipped with a computer for data acquisition; a cooling unit where the fluid flows through a copper serpentine immersed in water and ice; a reservoir; a peristaltic pump (VerderFlex Smart S10C) by which the fluid was repressed towards the heating chamber and the High Tension Source to apply the EHD effect. All details can be viewed in Fig. 2.

The hoses used were of polyurethane since this polymer has good resistance to the circulation of different fluids. Also, this type of hose allows the use of pneumatic connections that worked properly in the developed system and are easy to handle.

\subsection{Analysis of roughness and surface deposition}

It is well-known that the surface quality influences the thermal transfer rate and, in case of nanofluids, also influences the deposition process of nanoparticles on the heated surface. For this reason, the copper rod was polished prior to the experiment.

The surface roughness was measured before and after the tests employing a portable Time Group model TR200 roughness tester. The arithmetic average roughness (Ra) was measured using a cut-off of $0.8 \mathrm{~mm}$. Also, the surface aspect was observed by means of a Scanning Electron Microscope (SEM) - ZEISS EVO LS15 - with the detector operating with a $15 \mathrm{kV}$ electron beam and the chemical characterization of the heated surface was made by an Energy-Dispersive Spectroscopy (EDS) which was coupled to the SEM.

\subsection{Electric field application}

The generation of the electric field was done by a DC High Voltage
Low Current Power (ISB model 20kV5W) with adjustment between 0 and $20 \mathrm{kV}$. Two AISI 316 stainless steel plates with dimension of $14 \mathrm{~mm} \times 29 \mathrm{~mm}$ were positioned in the external lateral region of the heating chamber near to the heated rod as can be seem in Fig. 3. The distance between the plates was $30 \mathrm{~mm}$ and the applied voltage was $10 \mathrm{kV}$. Thus, the electric field generated was of $330 \mathrm{kV} / \mathrm{m}$.

\subsection{Nanofluids preparation}

The nanoparticles used in tests were manufactured by TNS Nanotecnologia Ltda. A Transmission Electron Microscopy (TEM) image is presented in Fig. 4. As can be seem, the silver nanoparticles have a spherical shape and mean diameter of $20 \mathrm{~nm}$.

In other researches $[39,40]$, the base fluid was a solution of ethylene glycol and deionized-water with a volume ratio of $56 \%$ and $44 \%$, respectively. The volumetric concentrations of nanoparticles were $0.039 \%$ and $0.078 \%$.

Considering that the nanoparticles were dispersed in a solution of EG, the first step was to calculate the amount of this solution necessary to achieve the desired nanoparticles concentration. After that, the additional EG and the DI-water were calculated and then, weighted in a precision analytical balance. Since obtained the correct amounts of $\mathrm{Ag}$ / EG, EG and DI-water for each condition, they were mixed by mechanical agitation. The nanofluid was not subject to the process of ultrassonication because the nanoparticles were already in a stable solution of EG and this process could negatively affect the stability of the nanofluid. It is worth mentioning that the final volume of each solution was of $350 \mathrm{ml}$.

A sample of nanofluid was produced with 0.078 vol\% and no sedimentation was verified during $6 \mathrm{~h}$. Therefore, it can be considered that the tests were carried out in a quasi-state condition since each test lasted $35 \mathrm{~min}$. Despite the verified stability of the nanofluid it is important to have in mind that the experimental tests were carried out in a dynamic condition where the nanofluid was circulating in a closed system and, due to the circulation, the stability could be influenced.

\subsection{Experimental procedure}

The flow rate during the tests was of $0.4 \mathrm{~L} / \mathrm{min}$ due to the pump capacity and each test took $35 \mathrm{~min}$. It is important to mention that this time represent the total time of fluid circulation. However the period of data acquisition was from 26 to $35 \mathrm{~min}$, after achieving the steady state condition. Two different concentrations of nanoparticles and the application of the Electrohydrodynamic Effect (EHD) were analyzed and, considering the base fluid without nanoparticles, there were a total of 6 different conditions that can be visualized in Table 1. Each condition was performed 3 times and DI-water was used to clean the circulation system after all tests. This procedure was based in, after removing the nanofluid, circulating DI-water during $10 \mathrm{~min}$.

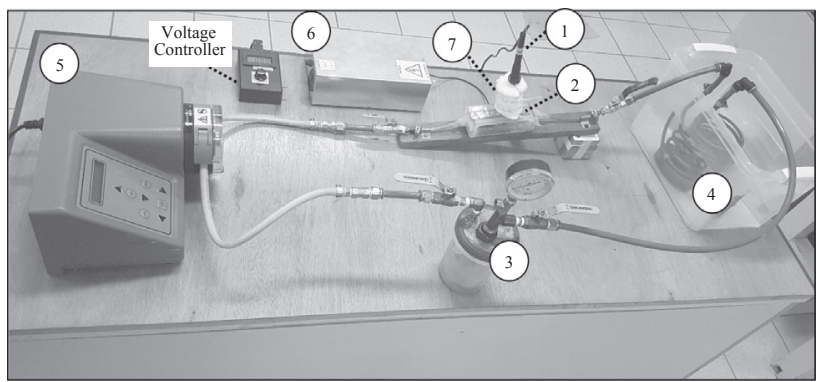

Fig. 2. Experimental apparatus:(1) Heating source; (2) Heat chamber; (3) Reservoir; (4) Cooling unit; (5) Peristaltic pump; (6) High tension source; (7) Thermal insulation. 


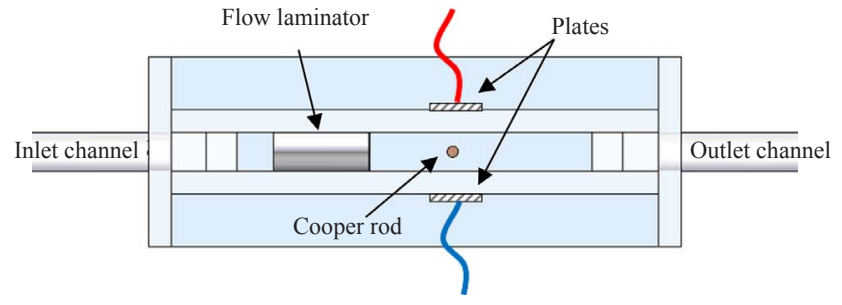

Fig. 3. Top view: application of the electric field on the experimental apparatus.

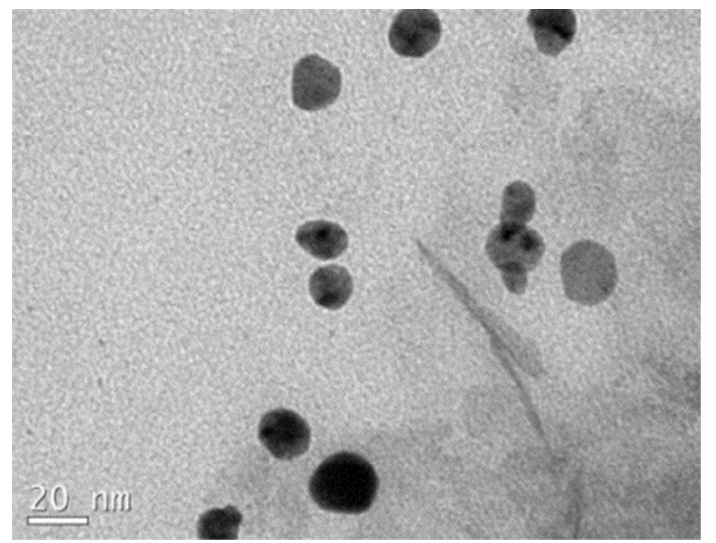

Fig. 4. TEM images of the nanoparticles. Provided by: TNS Solution Ltda.

Table 1

Experimental conditions.

\begin{tabular}{llll}
\hline Condition & Fluid & $\begin{array}{l}\text { Volumetric concentration of } \\
\text { nanoparticles }(\%)\end{array}$ & $\begin{array}{l}\text { Electric Field } \\
(\mathrm{kV} / \mathrm{m})\end{array}$ \\
\hline 1 & EG+DI- & - & Absent \\
2 & water & - & 330 \\
3 & EG+DI- & 0.039 & Absent \\
4 & water & & 330 \\
5 & EG+DI- & 0.078 & Absent \\
6 & water & & 330 \\
\hline
\end{tabular}

\subsection{Viscosity measurement and theoretical models}

With respect to the absolute viscosity of nanofluids, there are in literature several models [41-45]. These models only consider the nanoparticle concentration and the viscosity of the base fluid. The used models as references are presented in Table 2.

Where $\varnothing$ represents the volumetric concentration of nanoparticles and $\mu_{\mathrm{nf}}$ and $\mu_{\mathrm{f}}$ the absolute viscosities of the nanofluid and the basefluid, respectively.

In this work, the viscosity measurements were performed by a Brookfield LVDV-IIIU, cone-plate type Rheometer. The spindle used was the CPE-40 and the volume of each sample was $0.5 \mathrm{ml}$.

\subsection{Analysis of the convective heat thermal coefficient}

For the analysis of the thermal transfer coefficient, some considerations have been taken to solve the problem, such as: (a) the copper rod is an extended surface, with uniform cross sectional area and adiabatic tip; (b) one-dimensional conduction along the rod; (c) the radiant exchange with the neighborhood is negligible; (d) internal energy generation is null; (e) steady-state conditions; (f) constant properties of the fluids and rod; (g) uniform convective heat transfer coefficient.

According to Incropera and Dewitt [46], the temperature distribution for fins with uniform cross section and adiabatic tip are given by the Eq. (1).
Temperature distribution $\left(\theta / \theta_{\mathrm{b}}\right)$ :

$\frac{\theta(x)}{\theta_{b}}=\frac{\cosh m(L-x)}{\cosh m L}$

where $L$ is the length of the fin (cooper rod); $m$ is parameter related with the geometric characteristics of the fin and the heat transfer coefficient; $\theta(x)$ and $\theta_{b}$ represent the temperature in excess in a specific point of the fin and on its base, respectively, considering the average temperature of the fluid. Thereby, $\theta$ and $\theta_{b}$ are calculated by Eqs. (2) and (3):

$\theta(x)=T(x)-T_{\infty}$

$\theta_{b}=T_{b}-T_{\infty}$

where in $T_{\infty}$ is the media temperature (average between inlet and outlet fluid temperature in the chamber). To calculate $m$, the Eq. (4) is used:

$m^{2}=\frac{h P}{k A_{t r}}$

where $h$ is the convective heat transfer coefficient; $P$ and $A_{t r}$ are the perimeter and the area of the fin cross-section, respectively; $k$ is the thermal conductivity of the fin.

In this way, to calculate the temperature distribution for all extension of the fin it is used the Eq. (5).

$T(x)=T_{\infty}+\left(T_{b}-T_{\infty}\right) \cdot \frac{\cosh m(L-x)}{\cosh m L}$

To obtain the $T_{b}$ and $m$ values, that where not known, the use of the software MATLAB ${ }^{\oplus}$ 2013a was necessary. The function "curve fitting" adjusted the acquired temperature points $\left(T_{1}, T_{2}\right.$ and $\left.T_{3}\right)$ to a curve by the Ordinary Least Square Method and, as return, the values of $T_{b}$ and $m$.

Considering the calculations carried out, some properties of the base fluid have been defined, as well as the flow characteristics of the fluid and region where the thermal transfer took place. The properties of the EG + DI-water solution (56\%/44\%) were obtained from the MEGlobal catalog [47], for an average temperature of $14^{\circ} \mathrm{C}$. Thus, the following values were taken: $\quad c_{p}=3301 \mathrm{~J} / \mathrm{kg} \cdot \mathrm{K} ; \quad k=0.3937 \mathrm{~W} / \mathrm{m} \cdot \mathrm{K}$; $\mu=5.97 \mathrm{mPa} \cdot \mathrm{s} ; \rho=1055.7 \mathrm{~kg} / \mathrm{m}^{3}$.

\subsection{Uncertainties and validation of the experimental data}

The parameters $m$ and $T_{b}$ were determined by a computational statistics code with a $95 \%$ confidence level. So, these values are used to determine the heat transfer coefficient uncertainty based on the Eq. (4). In this case, the methodology presented by Kline and McClintock [48] was used to estimate the experimental uncertainties considering the instruments error and statistics parameters. It is possible to see on Table 3 the experimental uncertainties associated with each parameter. The calculated uncertainty for the heat transfer coefficient $(h)$ was obtained as $15 \%$ and it is mainly attributed to the uncertainties of $m$ parameter. The uncertainty of the viscosity of $\pm 1 \%$ was determined based on the data provided by the rheometer manufacturer. The maximum uncertainties for Reynolds and Nusselt number, also determined by the Kline and McClintock [48] method, is $\pm 3.3 \%$ and $\pm 15 \%$,

Table 2

Theoretical models for viscosity.

\begin{tabular}{ll}
\hline Author & Equation \\
\hline Einstein [41] & $\mu_{n f}=(1+2.5 \varnothing) \mu_{f}$ \\
Brinkman-Roscoe [42] & $\mu_{n f}=\frac{1}{(1-\varnothing)^{2.5}} \mu_{f}$ \\
Vand [43] & $\mu_{n f}=\left(1+2.5 \varnothing+7.349 \varnothing^{2}\right) \mu_{f}$ \\
Batchelor [44] & $\mu_{n f}=\left(1+2.5 \varnothing+6.2 \varnothing^{2}\right) \mu_{f}$ \\
Bruijin [45] & $\mu_{n f}=\frac{1}{\left(1-2.5 \varnothing+1.552 \varnothing^{2}\right)} \mu_{f}$ \\
\end{tabular}


Table 3

Experimental uncertainties.

\begin{tabular}{ll}
\hline Parameter & Uncertainty \\
\hline Perimeter, P (m) & $\pm 88.6 \mu \mathrm{m}$ \\
$\mathrm{m}_{\left(\mathrm{m}^{-1}\right)}$ & $\pm 8.0 \%$ \\
Cross-sectional area, Atr $\left(\mathrm{m}^{2}\right)$ & $\pm 3.9 \times 10^{-7} \mathrm{~m}^{2}$ \\
Fluid speed, V (m/s) & $\pm 3 \%$ \\
Diameter, D (m) & $\pm 50 \mu \mathrm{m}$ \\
Viscosity, $\mu$ (Pa·s) & $\pm 1 \%$ \\
Volumetric Flow, Q (L/min) & $\pm 2 \%$ \\
\hline
\end{tabular}

respectively.

In order to validate the experiments, deionized water was used in the experimental apparatus in a condition of external convection with laminar flow. Nusselt number was compared with well-known empirical equations. According to the results, the predictions and the experimental results are in good agreement. For Zukauskas [49], Hilpert [50] and Churchill and Bernstein [51] methods, the difference between the calculated Nusselt number and the predictions were of $9.4 \%, 14.8 \%$ and $7.3 \%$, respectively, as can be seem in Table 4 . It is worth mentioning that for these empirical expressions, it is not expected an accuracy better than $20 \%$.

\section{Results and discussion}

\subsection{Viscosity of nanofluids}

The dynamic viscosity of nanofluids is fundamental and experimental data were obtained and compared with some already known theoretical models.

For the pure solution of EG + DI-water in the temperature of $14{ }^{\circ} \mathrm{C}$, the dynamic viscosity is $5.97 \mathrm{mPa} \cdot \mathrm{s}$ [47]. This value was used to calculate the theoretical viscosity using the different models.

The values of the dynamic viscosity for different theoretical models and the experimental results are presented in Fig. 5. The influence that the concentration of nanoparticles has on the dynamic viscosity is evident. An increase of $24 \%$ in the dynamic viscosity, according to Vand Model, can be verified in the condition of higher concentration. Considering the experimental results, increases of $8.13 \%$ and $20.3 \%$ were achieved for volumetric concentrations of $0.039 \%$ and $0.078 \%$, respectively.

It is observed that the variation of the experimental viscosity values presented the same tendency of the theoretical models. In addition, it is worth mentioning that the values acquired were, generally, lower than the estimated values, even the difference being lower than $2.5 \%$ in all cases.

Viscosity measurements were performed at temperatures from $11^{\circ} \mathrm{C}$ to $15^{\circ} \mathrm{C}$, since the average temperature of the fluids in the heat chamber during the experiments was within this range. The dynamic viscosities for each nanofluid in different temperatures are presented in Fig. 6 . The higher increase is verified for $14^{\circ} \mathrm{C}$, where the difference between the viscosity of the base fluid and the nanofluid $(0.078 \mathrm{vol} \%)$ achieved $20.3 \%$.

Also, the Reynolds number (Re) was calculated for all conditions considering that, except by the viscosity, the fluid speed, specific mass and fin diameter were constant. The viscosity considered was for the temperature of $14^{\circ} \mathrm{C}$ because it was the average temperature of the fluid in the heat chamber. The Re number varied between 16.0 and 19.2 characterizing a laminar flow.

\subsection{Heated surface analysis}

In order to identify the deposition of nanoparticles, data related to the surface roughness, SEM images and the analysis of the chemical composition of the heated surface are presented.
The Fig. 7 shows a visual comparison between the rod before and after the conclusion of the experiments with $0.078 \mathrm{vol} \%$. It is worth mentioning that the rod was polished before the tests. It is possible to verify a clear change between the initial and final condition of the rod and to realize, even without the use of microscopes, that the surface was modified due to a chemical reaction with the cooper or nanoparticles deposition. However, the chemical reaction is not considered because the tests using the pure solution of EG + DI-water had not altered the fin surface. Despite of the nanoparticles deposition on the heated surface, no visual sedimentation was verified on the circulation system (internal parts of the hoses, reservoir and heat chamber), but considering a non-visual scale of the nanoparticles and what happened in the rod, it is possible that a minor amount of nanoparticles had deposited in the system.

Fig. 8 presents the surface roughness measured before and after the tests. An increase higher than 20 times was noticed for the concentration of $0.078 \%$. It is possible to confirm that the nanoparticles deposition really happened in the heated surface and that the surface was altered. Consequently, all these changes would influence the value of the heat transfer coefficient. Many authors justified the deterioration process of the heat transfer coefficient due to the nanoparticles deposition on the heated surface $[52,53]$. The conclusions proposed by $\mathrm{Qu}$ and $\mathrm{Wu}[54]$ states that the nature of the nanoparticle also influences the deterioration of the heat transfer coefficient because, for similar conditions with different base fluids or nanoparticles, the deposition process can be an advantage or a disadvantage.

The analyses using Energy-dispersive X-ray spectroscopy (EDS) carried out after the tests with $0.078 \mathrm{vol} \%$, were useful to characterize the composition of the heated surface and to identify the presence of different elements. According to Fig. 9, measurements indicated that about $20 \%$ of the surface composition was silver in the $T_{1}$ and $T_{2}$ regions, while in the $T_{3}$ region this value decreased to $3.5 \%$. The difference can be justified by the gradient of the fluid speed in the inner region of the chamber, considering that the region $T_{3}$ was the lowest one because of the chamber geometry. Moreover, different elements were found such as small amounts of Si and Al. The presence of Si and C can be explained by the utilization of sand paper composed by $\mathrm{SiC}$ during the first step of the polishing process. In the second step, a polishing paste composed by $\mathrm{Al}_{2} \mathrm{O}_{3}$ was used, justifying the presence of $\mathrm{Al}$. The presence of $\mathrm{O}$ is an evidence that oxidation may had happened resulting in an oxide layer.

Fig. 10 presents the images of regions $T_{1}, T_{2}$ and $T_{3}$ with a magnification of $100 \times$ before and after performing all tests. No material deposition was visible in previous conditions. The surfaces were clear and the scratches that are indicated by the arrows were results of the sanding and polishing processes. after the tests was not possible to see any sanding marks or scratches. The surface was modified by the presence of clusters of silver nanoparticles that were deposited or oxides that were formed during the deposition process, considering the temperature and the abundant presence of oxygen. In region $T_{1}$ there are larger clusters accumulation than in the region $T_{2}$ and $T_{3}$. Again this greater accumulation is justified by the flow profile and by the inclination of the chamber $\left(17^{\circ}\right)$, favoring a higher flow in the region $T_{1}$. The arrows indicate regions where clusters of nanoparticles or oxides were deposited on the surface. Further, a Region A is highlighted and presented in details in Fig. 11.

An analysis of the deposited layer is presented in Fig. 11 where a magnification of $2000 \times$ was made of the Region A (indicated in

Table 4

Comparison between calculated and experimental Nusselt number.

\begin{tabular}{llll}
\hline $\mathrm{Nu}$ & Hilpert & Zukauskas & Churchill \& Bernstein \\
\hline 21.37 & 18.33 & 19.49 & 19.95 \\
Variation & $14.8 \%$ & $7.3 \%$ & $9.4 \%$ \\
\hline
\end{tabular}




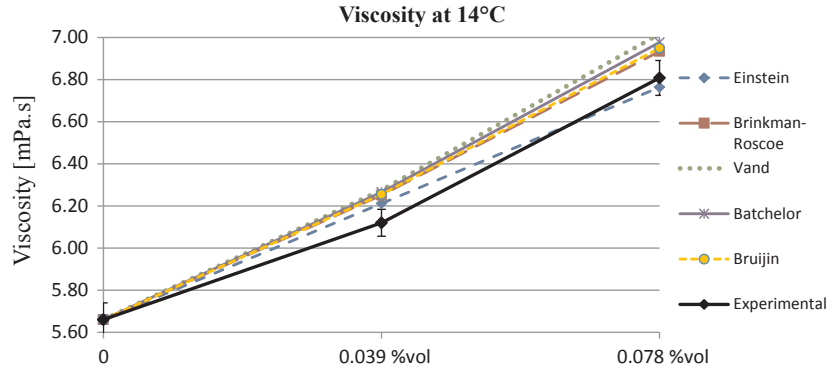

Fig. 5. Theoretical and experimental viscosity.

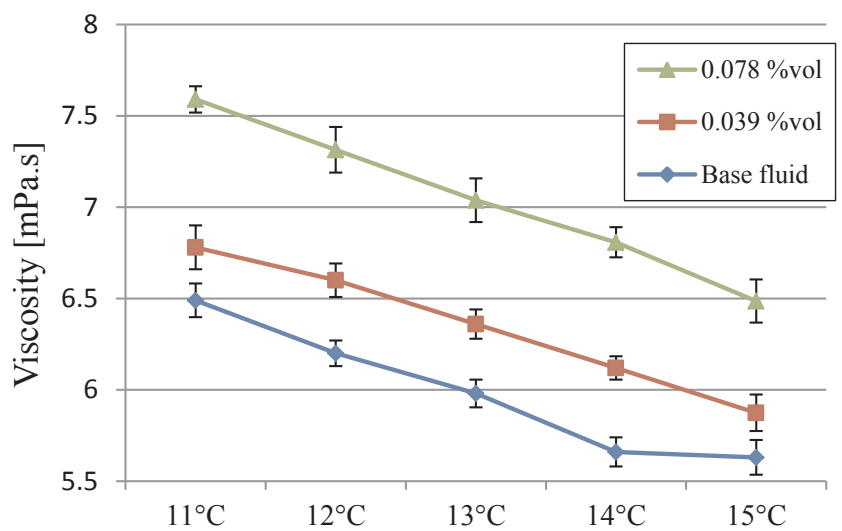

Fig. 6. Dynamic viscosity in function of temperature.

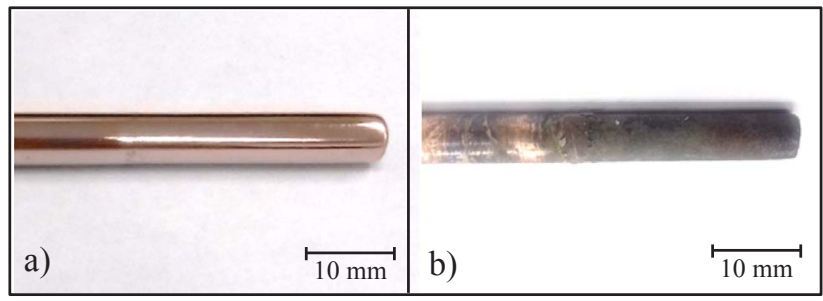

Fig. 7. Copper rod (a) before and (b) after the tests.

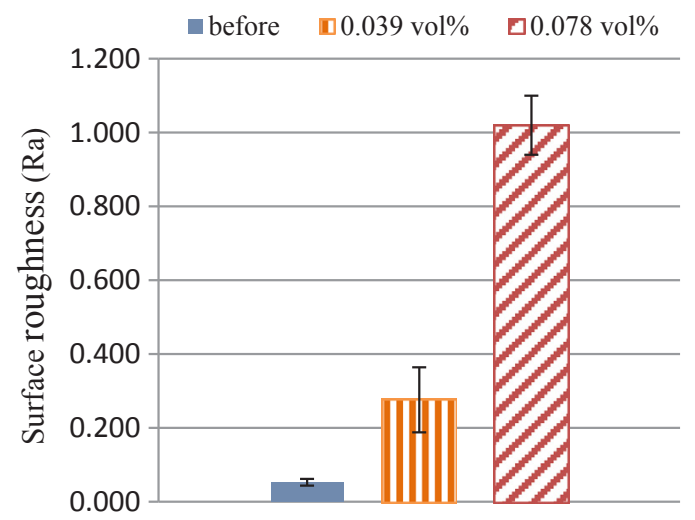

Fig. 8. Surface roughness of the cooper rod before and after the tests.

Fig. 10). The darker spots present in the SEM image and highlighted by the arrows can be considerate porous where there was no deposition of nanoparticles or the amount of deposited material was lesser than the surrounding region. Besides that, it is also possible to identify the formation of sheets which represent thin layers of deposited material. So, merge as a hypothesis, the fact that internal porous can be formed between the superimposed layers. Furthermore, this porous would represent a thermal barrier within the deposited layer and could be empty

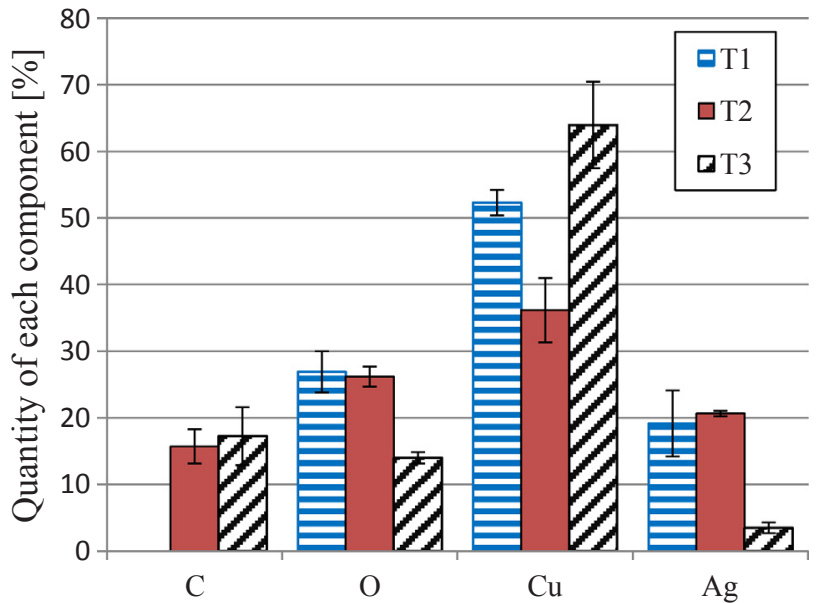

Fig. 9. Chemical composition of the heated surface.

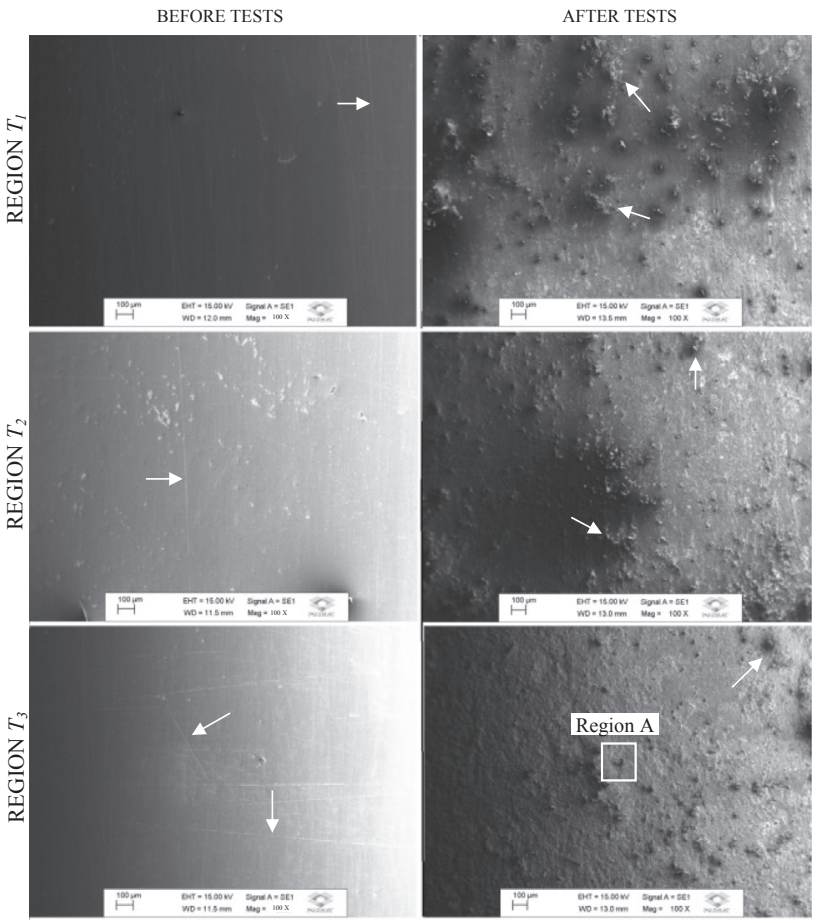

Fig. 10. SEM images $(100 \times)$ showing the deposition of nanoparticles over the copper surface before and after the tests.

spots or filled with the basefluid.

Considering this sheets, merge as a hypothesis the fact that internal porous can be formed between the sheets or between the rod and the silver layer. Furthermore, this porous would represent a thermal barrier within the deposited layer and could be empty spots or filled with the basefluid.

\subsection{Convective heat transfer coefficient}

The convective heat transfer coefficient value $(h)$ was estimated applying the principle of reverse heat transfer. Thus, one cooper rod was considered as a fin with uniform cross section with adiabatic tip. The temperature distribution profile and heat loss equation were used to determine the values of the fin base temperature $\left(T_{b}\right)$ and the parameter $m$.

This procedure were applied to some tests and the Table 5 shows the $T_{b}$ and $m$ values provided by the least squares method with $95 \%$ 


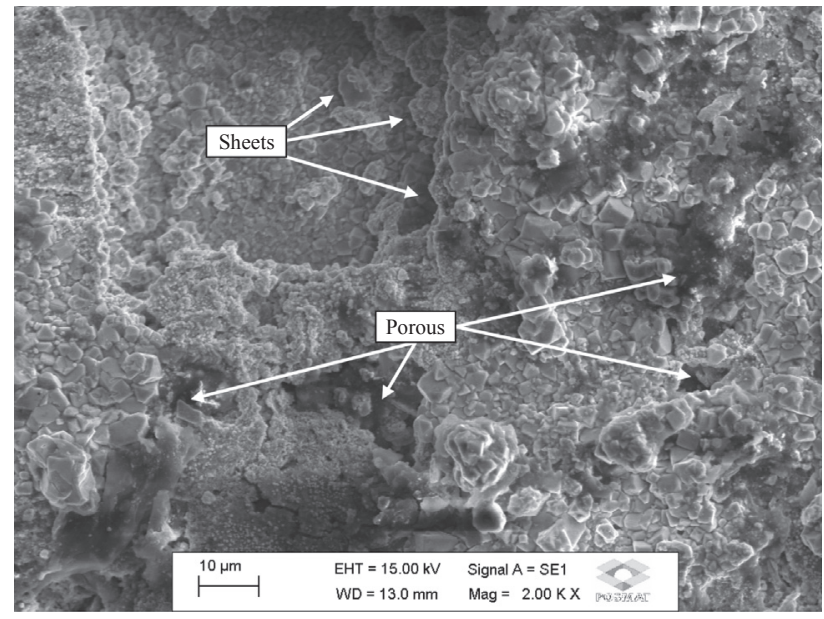

Fig. 11. SEM images made of the Region A (Fig. 10) with magnifications of $2000 \times$ in region $T_{3}$.

Table 5

Information and parameters obtained by MATLAB ${ }^{\oplus}$ processing.

\begin{tabular}{lllc}
\hline Condition & & $m\left(\mathrm{~m}^{-1}\right)$ & $T_{b}\left({ }^{\circ} \mathrm{C}\right)$ \\
\hline 1 & $\begin{array}{l}\text { EG + DI-water } \\
\text { Reference }\end{array}$ & 45.15 & 104.6 \\
2 & $\begin{array}{l}\text { EG + DI-water } \\
\text { EHD }\end{array}$ & 47.07 & 103 \\
3 & $\begin{array}{l}\text { EG + DI-water } \\
\text { 0.039 vol\% }\end{array}$ & 45.75 & 123.3 \\
4 & $\begin{array}{l}\text { EG + DI-water } \\
0.039 \text { vol\% + EHD }\end{array}$ & 47.54 & 114.3 \\
5 & $\begin{array}{l}\text { EG + DI-water } \\
0.078 \text { vol\% } \\
\text { EG + DI-water } \\
0.078 \text { vol\% + EHD }\end{array}$ & 41.64 & 104.9 \\
& & 42.69 & 97.38 \\
\hline
\end{tabular}

reliability. In order to obtain the approximated equation, the average temperatures of the fluid were used and all the procedure was performed using MATLAB $^{\circledR}$ software.

Considering the definition of the parameter $m$ defined on Eq. (4), it is possible to calculate the convective heat transfer coefficient. The values of $h$ are presented in Fig. 12 for each condition.

Considering the definition of the parameter $m$ defined on Eq. (4), it is possible to calculate the convective heat transfer coefficient. The values of $h$ are presented in Fig. 12 for each condition.

Taking into account previous researches, it was expected an increase in the heat transfer coefficient $(h)$ values with the increase of nanoparticles concentration. It was also expected that the application of the Electrohydrodynamic Effect would result in a more expressive increase in the $h$ values.

In the conditions with the same concentration, but including the EHD, there is an increase in the heat transfer coefficient. This behavior is analogous to previous work such as Allen and Karayiannis [23]. Except by the dielectrophoresis, which occurs only when a non-uniform electric field is applied, the corona effect and electrophoresis have positive influence on the heat transfer coefficient. Increases of $8.7 \%, 8 \%$ and $6.4 \%$ in heat transfer coefficient were achieved in comparisons between conditions 1 and 2; 3 and 4; and 5 and 6, respectively. Thus, among all conditions analyzed, the highest value of the heat transfer coefficient $(h)$ was for 0.039 vol\% with EHD, resulting in an increase of $11 \%$ compared to the base fluid. On the other hand, the worst condition was attained with the greater concentration and without the EHD, which represented a decrease of $15 \%$ in the heat transfer coefficient $(h)$. It is important to keep in mind that the concentration of $0.078 \mathrm{vol} \%$ increased the viscosity of the fluid in $20 \%$ reducing the heat transfer coefficient $(h)$. Furthermore, the higher volumetric concentration implies in an intensification of nanoparticle deposition on the heated surface, as showed in Fig. 11.

These results are in agreement with Asadzadeh et al. [26], where higher concentrations led to an increase in viscosity and nanoparticles deposition, impairing the heat flux. The influence of the deposition was also highlighted by Moreira et al. [22] where a decrease in the heat transfer coefficient was verified in some conditions which the nanoparticles deposition was verified.

With the application of the EHD effect, the reduction on the heat transfer coefficient was attenuated and, according to Asadzadeh et al. [26], this is due to the fact that electric forces introduce disturbances in the boundary layer that increase the heat transfer and corroborate to reduce the negatively effect of the nanoparticles deposition and viscosity increase.

Thus, in agreement with the presented data, it is important to emphasize that the concentration of $0.078 \mathrm{vol} \%$ modified the viscosity of the fluid reducing the heat transfer coefficient $(h)$. Furthermore, the higher volumetric concentration implies in an intensification of nanoparticle deposition on the heated surface.

It is worth mentioning that the deposition of silver nanoparticles by itself cannot be considered a satisfactory explanation for the decrease in the heat transfer coefficient because the thermal conductivity of silver $(429 \mathrm{~W} / \mathrm{m} \cdot \mathrm{K})$ and cooper $(401 \mathrm{~W} / \mathrm{m} \cdot \mathrm{K})$ are close and a layer composed exclusively of silver nanoparticles would not represent a thermal resistance. However, considering the EDS analyze and the amount of oxygen on the surface, the presence of oxides represents a thermal resistance that would result in the heat transfer coefficient degradation.

Moreover, the nanoparticles deposition occurred in absence of pressure, so, it is possible to have the formation of porous within the silver oxide layer or between the silver nanoparticles and the cooper surface, as presented in Fig. 11. It is known that the presence of these porous would represent a thermal resistance, even if filled with liquid.

\section{Conclusions}

The higher value for the heat transfer coefficient $(h)$ was obtained with the lower volumetric concentration. When the EHD effect was applied, the heat transfer coefficient increased further more by about $11 \%$. At the highest concentration, the value of the heat transfer coefficient $(h)$ was reduced due to the effect of the deposition of nanoparticles on the heated surface and the increase of the viscosity of the nanofluid.

The increase in nanoparticle concentration implied reductions in viscosity values. This reduction reached the maximum of $20.3 \%$ for the temperature of $14^{\circ} \mathrm{C}$.

In this study it was observed that nanoparticles deposited on the heated surface and this may represent an important limitation when this layer becomes a thermal resistance either by the formation of

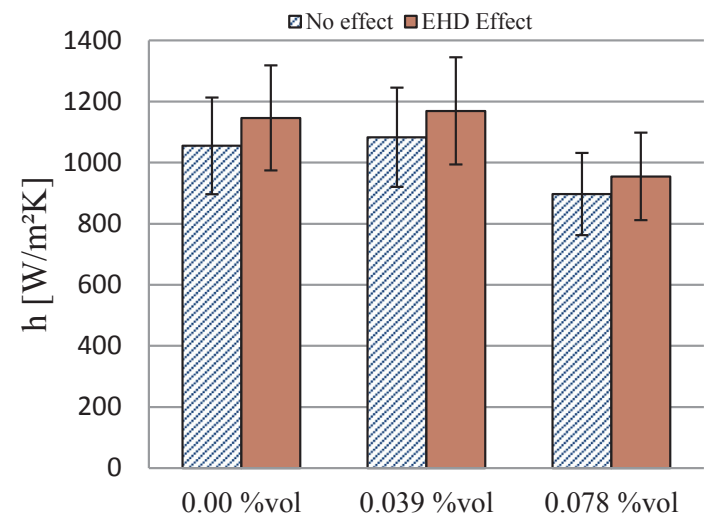

Fig. 12. Heat transfer coefficient $(h)$ for each experimental condition. 
oxides or by the presence of pores. Because of this deposition, the surface roughness of the rod after the tests was approximately 20 times higher than at the beginning of the tests in the condition with the higher concentration.

Thus, it can be concluded that the interaction between nanoparticles is evident and the heated surface as well as the nanofluid stability are fundamental in practical applications of heat transfer.

\section{References}

[1] S.U.S. Choi, J.A. Eastman, Enhancing thermal conductivity of fluids with nanoparticles, ASME Int. Mech. Eng. Congr. Expo. (1995).

[2] J. Sarkar, A critical review on convective heat transfer correlations of nanofluids, Renew. Sustain. Energy Rev. 15 (2011) 3271-3277, http://dx.doi.org/10.1016/j. rser.2011.04.025.

[3] S. Laohalertdecha, P. Naphon, S. Wongwises, A review of electrohydrodynamic enhancement of heat transfer, Renew. Sustain. Energy Rev. 11 (2007) 858-876, http://dx.doi.org/10.1016/j.rser.2005.07.002.

[4] S. Lee, S.U.-S. Choi, S. Li, J.A. Eastman, Measuring thermal conductivity of fluids containing oxide nanoparticles, J. Heat Transfer. 121 (1999) 280, http://dx.doi. org/10.1115/1.2825978.

[5] M.H. Aghabozorg, A. Rashidi, S. Mohammadi, Experimental investigation of heat transfer enhancement of Fe2O3-CNT/water magnetic nanofluids under laminar, transient and turbulent flow inside a horizontal shell and tube heat exchanger, Exp. Therm. Fluid Sci. 72 (2016) 182-189, http://dx.doi.org/10.1016/j.expthermflusci. 2015.11.011.

[6] T.B. Gorji, A.A. Ranjbar, A numerical and experimental investigation on the performance of a low-flux direct absorption solar collector (DASC) using graphite, magnetite and silver nanofluids, Sol. Energy. 135 (2016) 493-505, http://dx.doi. org/10.1016/j.solener.2016.06.023.

[7] J.A. Eastman, S.U.S. Choi, S. Li, L.J. Thompson, S. Lee, Enhanced thermal conductivity through the development of nanofluids, MRS Proc. 457 (1997) 3-11, http://dx.doi.org/10.1557/PROC-457-3.

[8] S.K. Das, N. Putra, W. Roetzel, Pool boiling characteristics of nano-fluids, Int. J. Heat Mass Transf. 46 (2003) 851-862, http://dx.doi.org/10.1016/S0017-9310(02) 00348-4.

[9] W. Yu, S.U.S. Choi, The role of interfacial layers in the enhanced thermal conductivity of nanofluids: a renovated maxwell model, J. Nanoparticle Res. 5 (2003) 167-171, http://dx.doi.org/10.1023/A:1024438603801.

[10] C.-J. Yu, A. Richter, A. Datta, M. Durbin, P. Dutta, Molecular layering in a liquid on a solid substrate: an X-ray reflectivity study, Phys. B Condens. Matter. 283 (2000) 27-31, http://dx.doi.org/10.1016/S0921-4526(99)01885-2.

[11] J. Buongiorno, Convective transport in nanofluids, J. Heat Transfer. 128 (2006) 240, http://dx.doi.org/10.1115/1.2150834.

[12] S. Sarbolookzadeh Harandi, A. Karimipour, M. Afrand, M. Akbari, A. D’Orazio, An experimental study on thermal conductivity of F-MWCNTs-Fe3O4/EG hybrid nanofluid: Effects of temperature and concentration, Int. Commun. Heat Mass Transf. 76 (2016) 171-177, http://dx.doi.org/10.1016/j.icheatmasstransfer.2016.05.029.

[13] H. Xie, J. Wang, T. Xi, Y. Liu, Thermal conductivity of suspensions containing nanosized SiC particles, Int. J. Thermophys. 23 (2002) 571-580, http://dx.doi.org/10. 1023/A:1015121805842.

[14] H. Xie, J. Wang, T. Xi, Y. Liu, Study on the thermal conductivity of SiC nanofluids, J. Chinese Ceram. Soc. 29 (2001) 361-364.

[15] S.W. Lee, S.D. Park, S. Kang, I.C. Bang, J.H. Kim, Investigation of viscosity and thermal conductivity of $\mathrm{SiC}$ nanofluids for heat transfer applications, Int. J. Heat Mass Transf. 54 (2011) 433-438, http://dx.doi.org/10.1016/j.ijheatmasstransfer. 2010.09.026.

[16] M. Baratpour, A. Karimipour, M. Afrand, S. Wongwises, Effects of temperature and concentration on the viscosity of nanofluids made of single-wall carbon nanotubes in ethylene glycol, Int. Commun. Heat Mass Transf. 74 (2016) 108-113, http://dx. doi.org/10.1016/j.icheatmasstransfer.2016.02.008.

[17] A. Karimipour, A. Hossein Nezhad, A. D’Orazio, M. Hemmat Esfe, M.R. Safaei, E. Shirani, Simulation of copper-water nanofluid in a microchannel in slip flow regime using the lattice Boltzmann method, Eur. J. Mech. B/Fluids. 49 (2015) 89-99, http://dx.doi.org/10.1016/j.euromechflu.2014.08.004.

[18] A. Karimipour, New correlation for Nusselt number of nanofluid with $\mathrm{Ag} / \mathrm{Al} 2 \mathrm{O} 3 / \mathrm{Cu}$ nanoparticles in a microchannel considering slip velocity and temperature jump by using lattice Boltzmann method, Int. J. Therm. Sci. 91 (2015) 146-156, http://dx. doi.org/10.1016/j.ijthermalsci.2015.01.015.

[19] A. Karimipour, M. Hemmat Esfe, M.R. Safaei, D. Toghraie Semiromi, S. Jafari, S.N. Kazi, Mixed convection of copper-water nanofluid in a shallow inclined lid driven cavity using the lattice Boltzmann method, Phys. A Stat. Mech. Its Appl. 402 (2014) 150-168, http://dx.doi.org/10.1016/j.physa.2014.01.057.

[20] K. Henderson, Y.G. Park, L. Liu, A.M. Jacobi, Flow-boiling heat transfer of R-134abased nanofluids in a horizontal tube, Int. J. Heat Mass Transf. 53 (2010) 944-951, http://dx.doi.org/10.1016/j.ijheatmasstransfer.2009.11.026.

[21] K.J. Park, D. Jung, S.E. Shim, Nucleate boiling heat transfer in aqueous solutions with carbon nanotubes up to critical heat fluxes, Int. J. Multiph. Flow. 35 (2009) 525-532, http://dx.doi.org/10.1016/j.ijmultiphaseflow.2009.02.015.

[22] T.A. Moreira, F.J. do Nascimento, G. Ribatski, An investigation of the effect of nanoparticle composition and dimension on the heat transfer coefficient during flow boiling of aqueous nanofluids in small diameter channels $(1.1 \mathrm{~mm})$, Exp. Therm. Fluid Sci. 89 (2017) 72-89, http://dx.doi.org/10.1016/j.expthermflusci. 2017.07.020.

[23] P.H.G. Allen, T.G. Karayiannist, Electrohydrodynamic enhancement of heat transfer and fluid flow, Heat Recover. Syst. CHP. 15 (1995) 389-423.

[24] M. Robinson, Movement of air in the electric wind of the corona discharge, Trans. Am. Inst. Electr. Eng. Part I Commun. Electron. 80 (1961) 143-150.

[25] S.L. Tsai, J.L. Hong, M.K. Chen, L.S. Jang, Experimental study of dielectrophoresis and liquid dielectrophoresis mechanisms for particle capture in a droplet, Electrophoresis. 32 (2011) 1337-1347, http://dx.doi.org/10.1002/elps. 201000548.

[26] F. Asadzadeh, M. Nasr Esfahany, N. Etesami, Natural convective heat transfer of Fe3O4/ethylene glycol nanofluid in electric field, Int. J. Therm. Sci. 62 (2011) 114-119, http://dx.doi.org/10.1016/j.ijthermalsci.2011.11.010.

[27] S.Z. Heris, F. Mohammadpur, A. Shakouri, Effect of electric field on thermal performance of thermosyphon heat pipes using nanofluids, Mater. Res. Bull. 53 (2014) 21-27, http://dx.doi.org/10.1016/j.materresbull.2014.01.030.

[28] F. Klocke, G. Eisenblätter, Dry cutting - State of research, VDI Berichte. 46 (1998) 159-188, http://dx.doi.org/10.1016/S0007-8506(07)60877-4.

[29] P.S. Sreejith, B.K.A. Ngoi, Dry machining: machining of the future, J. Mater. Process. Technol. 101 (2000) 287-291, http://dx.doi.org/10.1016/S09240136(00)00445-3.

[30] R.D. Zerkle, Cooling System for Cutting Tool and the Like, 1971.

[31] R.Y. Chiou, L. Lu, J.S.J. Chen, M.T. North, Investigation of dry machining with embedded heat pipe cooling by finite element analysis and experiments, Int. J. Adv. Manuf. Technol. 31 (2007) 905-914, http://dx.doi.org/10.1007/s00170-0050266-8.

[32] C. Rozzi, W. Chen, E.E. Archibald, Indirect Cooling Of A Cutting Tool, 2011.

[33] V. Mauel, Cutting tool with device for indirect cooling of an indexable insert. EP1242214B1, 2001.

[34] H. Zhao, G.C. Barber, Q. Zou, A study of flank wear in orthogonal cutting with internal cooling, Wear. 253 (2002) 957-962, http://dx.doi.org/10.1016/S00431648(02)00248-X.

[35] S. Lagerber, Chip Forming Cutting Insert With Internal Cooling, 2000.

[36] L.W. Fan, J.Q. Li, D.Y. Li, L. Zhang, Z.T. Yu, K.F. Cen, The effect of concentration on transient pool boiling heat transfer of graphene-based aqueous nanofluids, Int. J. Therm. Sci. 91 (2015) 83-95, http://dx.doi.org/10.1016/j.ijthermalsci.2015.01. 009.

[37] L. Liang, Y. Quan, Investigation of heat partition in dry turning assisted by heat pipe cooling, Int. J. Adv. Manuf. Technol. 66 (2011) 1931-1941, http://dx.doi.org/10. 1007/s00170-012-4471-y.

[38] R.R. Ingraci Neto, R.L. Fragelli, A.A. Fiocchi, V.L. Scalon, L.E. de A. Sanchez, Toolholder internally cooled by a phase change fluid in turning of SAE XEV-F, Appl Mech. Mater. 798 (2015) 486-490, http://dx.doi.org/10.4028/www.scientific.net/ AMM.798.486.

[39] M.R. Raveshi, A. Keshavarz, M.S. Mojarrad, S. Amiri, Experimental investigation of pool boiling heat transfer enhancement of alumina-water-ethylene glycol nanofluids, Exp. Therm. Fluid Sci. 44 (2013) 805-814, http://dx.doi.org/10.1016/j. expthermflusci.2012.09.025.

[40] M. Sheikhbahai, M. Nasr Esfahany, N. Etesami, Experimental investigation of pool boiling of Fe3O4/ethylene glycol-water nanofluid in electric field, Int. J. Therm. Sci. 62 (2012) 149-153, http://dx.doi.org/10.1016/j.ijthermalsci.2011.10.004.

[41] A. Einstein, Eine neue Bestimmung der Molek??ldimensionen, Ann. Phys. 324 (1906) 289-306, http://dx.doi.org/10.1002/andp.19063240204.

[42] H.C. Brinkman, The viscosity of concentrated suspensions, J. Chem. Phys. 20 (1952) 571.

[43] V. Vand, Viscosity of solutions and suspensions. I. Theory, J. Phys. Chem. 52 (1948) 277-299.

[44] G.K. Batchelor, The effect of Brownian motion on the bulk stress in a suspension of spherical particles, J. Fluid Mech. 83 (1977) 97-117, http://dx.doi.org/10.1017/ S0022112077001062.

[45] H. Bruijn, The viscosity of suspensions of spherical particles, Recl. Des Trav. Chim. Des PayesBas. 61 (1942) 863-887.

[46] F.P. Incropera, D.P. Dewitt, Fundamentals of Heat and Mass Transfer, John Wiley \& Sons, 2003

[47] MEGlobal, Ethylene Glycol - Product Guide, 2008, pp. 18

[48] S.J. Kline, F.A. McClintock, Uncertainties in single-sample experiments, Mech. Eng. 75 (1953) 3-8.

[49] A. Žukauskas, Heat transfer from tubes in crossflow, Adv. Heat Transf. 8 (1972) 93-160, http://dx.doi.org/10.1016/S0065-2717(08)70038-8.

[50] R. Hilpert, Heat transfer from cylinders, Forsch. Geb. Ingenieurwes. 4 (1933) 215.

[51] S.W. Churchill, A comprehensive correlating equation for forced convection from flat plates, AIChE J. 22 (1976) 264-268, http://dx.doi.org/10.1002/aic 690220207.

[52] I.C. Bang, S. Heung Chang, Boiling heat transfer performance and phenomena of Al2O3-water nano-fluids from a plain surface in a pool, Int. J. Heat Mass Transf. 48 (2005) 2407-2419, http://dx.doi.org/10.1016/j.ijheatmasstransfer.2004.12.047.

[53] V. Sajith, M.R. Madhusoodanan, C.B. Sobhan, An experimental investigation of the boiling performance of water-based nanofluids, 2008 Proc. ASME Micro/Nanoscale Heat Transf. Int. Conf. MNHT 2008. PART A (2008) 555-561. http://doi.org/10. 1115/MNHT2008-52216.

[54] J. Qu, H. Wu, Thermal performance comparison of oscillating heat pipes with SiO2/ water and Al2O3/water nanofluids, Int. J. Therm. Sci. 50 (2011) 1954-1962, http://dx.doi.org/10.1016/j.ijthermalsci.2011.04.004. 